Original Research

\title{
Patterns of medication errors involving pediatric population reported to the French Medication Error Guichet
}

\author{
Christine AZAR (D), Delphine ALLUÉ, Marie B. VALNET-RABIER (D), Laurent CHOUCHANA (D), Fanny ROCHER, \\ Dorothée DURAND, Nathalie GRENÉ-LEROUGE, Nadine SALEH (iD), Patrick MAISON (D). \\ Received (first version): 29-Mar-2021 Accepted: 30-May-2021 Published online: 14-Jun-2021
}

\begin{abstract}
Background: Medication error is a global threat to patient safety, particularly in pediatrics. Yet, this issue remains understudied in this population, in both hospital and community settings.

Objectives: To characterize medication errors involving pediatrics reported to the French Medication Error Guichet, and compare them with medication errors in adults, in each of the hospital and community settings.

Methods: This was a retrospective secondary data analysis of medication errors reported throughout 2013-2017. Descriptive and multivariate analyses were performed to compare actual and potential medication error reports between pediatrics (aged $<18$ years) and adults (aged $>18$ and $<60$ years). Two subanalyses of actual medication errors with adverse drug reaction (ADR), and serious ADR were conducted.

Results: We analyzed 4,718 medication error reports. In pediatrics, both in hospital $(n=791)$ and community $(n=1,541)$ settings, antibacterials for systemic use $(n=121,15.7 \% ; n=157,10.4 \%$, respectively) and wrong dose error type $(n=391,49.6 \% ; n=549,35.7 \%$, respectively) were frequently reported in medication errors. These characteristics were also significantly more likely to be associated with reported errors in pediatrics compared with adults. In the hospital setting, analgesics (adjusted odds ratio (aOR) $=1.59 ; 95 \%$ confidence interval $(\mathrm{Cl})$ 1.03:2.45), and blood substitutes and perfusion solutions (aOR=3.74; $95 \% \mathrm{Cl} 2.24: 6.25$ ) were more likely to be associated with reported medication errors in pediatrics; the latter drug class ( $\mathrm{aOR}=3.02 ; 95 \% \mathrm{Cl}$ 1.59:5.72) along with wrong technique $(\mathrm{aOR}=2.28 ; 95 \% \mathrm{Cl} 1.01: 5.19)$ and wrong route $(\mathrm{aOR}=2.74 ; 95 \% \mathrm{Cl} 1.22: 6.15)$ error types related more to reported medication errors with serious ADR in pediatrics. In the community setting, the most frequently reported pediatric medication errors involved vaccines $(n=389,25.7 \%)$. Psycholeptics (aOR=2.42; $95 \% \mathrm{Cl} 1.36: 4.31)$ were more likely to be associated with reported medication errors with serious $A D R$ in pediatrics. Wrong technique error type $(a O R=2.71 ; 95 \% \mathrm{Cl} 1.47: 5.00)$ related more to reported medication errors with ADR in pediatrics.

Conclusions: We identified pediatric-specific medication error patterns in the hospital and community settings. Our findings inform focused error prevention measures, and pave the way for interventional research targeting the needs of this population.
\end{abstract}

Keywords

Medication Errors; Patient Safety; Drug-Related Side Effects and Adverse Reactions; Adverse Drug Reaction Reporting Systems; Pharmacovigilance; Pharmacoepidemiology; Child; Infant; Multivariate Analysis; Retrospective Studies; France

\section{INTRODUCTION}

In 1999, the Institute of Medicine published its landmark report "To Err is Human", which estimated that, in the United States, 44,000 to 98,000 deaths annually are due to

Christine AZAR. RN, MPH. Epidemiology in Dermatology and Evaluation of therapeutics, Paris-Est Creteil University. Creteil (France). azar.m.christine@gmail.com

Delphine ALLUÉ. PharmD. French National Agency for Medicines and Health Products Safety (ANSM). Saint-Denis, (France). delphine.allue@ansm.sante.fr

Marie-Blanche VALNET-RABIER. MD. Regional

Pharmacovigilance Center, University Hospital of Besancon.

Besancon (France). mbrabier@chu-besancon.fr

Laurent CHOUCHANA. PharmD, PhD. Regional Pharmacovigilance

Center, Cochin Hospital AP-HP.Centre - Paris University. Paris

(France). laurent.chouchana@aphp.fr

Fanny ROCHER. PharmD. Regional Pharmacovigilance Center,

University Hospital of Nice. Nice (France). ROCHER.F@chu-nice.fr

Dorothée DURAND. PharmD. French National Agency for

Medicines and Health Products Safety (ANSM). Saint-Denis,

(France). durand dorothee@yahoo.fr

Nathalie GRENÉ-LEROUGE. PharmD. French National Agency for

Medicines and Health Products Safety (ANSM). Saint-Denis,

(France). Nathalie.grene-lerouge@sante.gouv.fr

Nadine SALEH. MPH, PhD. Faculty of Public Health, Lebanese

University. Fanar (Lebanon). nadeensh@gmail.com

Patrick MAISON. MD, PhD. Creteil Intercommunal Hospital Center

(CHI Creteil). Creteil (France). patrick.maison@ansm.sante.fr medical errors, with 7,000 deaths attributable to medication errors. ${ }^{1}$ Since this publication, interest in medication errors has increased dramatically. ${ }^{2-4}$ Two decades later, medication errors are still estimated to injure approximately 1.3 million people in the United States annually. ${ }^{5}$ In England, out of the estimated 237 million medication errors per year, $27.8 \%$ have the potential to cause moderate and severe harm. ${ }^{6}$ In France, the Enquête Nationale sur les Evénements Indésirables graves liés aux Soins (ENEIS) study revealed that $42 \%$ of serious adverse drug events are preventable. ${ }^{7}$ In response to this problem, the World Health Organization (WHO) launched in 2017 its "Global Patient Safety Challenge on Medication SafetyMedication Without Harm" aiming to reduce severe, avoidable medication-associated harm by $50 \%$ over the next five years, specifically by prioritizing and effectively managing "high-risk situations".

Although medication errors constitute a major concern in different age groups, children are distinctively prone to this problem. ${ }^{9}$ Several factors heighten risk of medication errors in pediatrics, primordially the weight-based dosing that involves multiple calculations, in addition to the lack of appropriate pediatric formulations. ${ }^{9-11} \mathrm{~A}$ recent systematic 
review conducted in pediatric intensive care units reported a median rate of medication errors at 14.6 per 100 medication orders, and between 6.4 and 9.1 per 1,000 patient-days. ${ }^{12}$ In the community, medication errors involving children also occur frequently; reported data indicate an annual average of 63,358 young children in the United States experiencing medication errors, or one child every eight minutes. ${ }^{13}$ Moreover, pediatric patients are three times more likely than adults to experience potentially harmful medication errors. ${ }^{10}$

Patterns of medication errors in pediatrics are understudied in the hospital and community settings. ${ }^{14,15}$ Besides, using information from studies conducted on adults may be of limited value, since medication errors most likely differ between the two populations. ${ }^{16,17}$ Exploring specific patterns of medication errors in pediatrics compared with adults could enhance our understanding of this complex problem in pediatrics and inform targeted efforts to enhance patient safety.

In France, a national medication error reporting system, the French Medication Error Guichet, which is managed by the National Agency for Medicines and Health Products Safety, allows the collection of reported medication errors. ${ }^{18}$ Our study aimed to characterize the medication errors reported to the French Medication Error Guichet in pediatrics aged less than 18 years, and compare them with medication errors in adults, in each of the hospital and community settings.

\section{METHODS}

\section{Study design}

We performed a retrospective secondary data analysis of the medication errors reported to the French Medication Error Guichet over a five-year period from 2013 to 2017.

\section{Definitions}

According to the French National Agency for Medicines and Health Products Safety, medication error was defined as an unintentional omission or commission of an act during the care process involving a drug, which may cause a risk or an adverse event for the patient. ${ }^{19}$ There were three classifications for medication errors:

Actual medication error is an error that occurred and reached the patient. ${ }^{20}$ It may be associated or not with adverse drug reaction (ADR).

Potential medication error is an error that is intercepted before the administration of the medication to the patient. $^{20}$ Therefore, potential medication error does not allow analysis on ADRs.

Medication error risk is an observation that witnessed a potential danger to the patient. ${ }^{20}$ The patient description (age, gender) and error characterization (stages, types) are not applicable in case of error risk. Consequently, medication error risk does not allow an age-based analysis.

The age group categories followed the classification adopted by the French Medication Error Guichet: pediatrics (age $<18$ years), adults (age $>18$ and $<60$ years), and geriatrics (age $>60$ years).

\section{Inclusion/exclusion criteria}

All actual and potential medication error reports involving pediatric and adult populations submitted to the French Medication Error Guichet between 2013 and 2017 were included in the analysis.

Reports of medication error risk, reports of medication errors involving geriatric population, and reports with unknown patient age or error setting were excluded from the analysis.

\section{Data sources}

The French Medication Error Guichet is a centralized database for collecting all medication error reports (medication error risk, potential, and actual medication errors) occurring in France. Medication errors were reported by the regional pharmacovigilance centers network, pharmaceuticals laboratories, healthcare professionals, and patients. Medication errors without ADRs were reported voluntarily. However, medication errors with ADRs were reported on a mandatory basis for healthcare professionals, through the regional pharmacovigilance centers network.

\section{Data collection}

Collected data included the person who reported the error (profession, workplace of the declarant), patient (gender, age), error description (date of occurrence, setting, classification, stages, types, and causes), products involved (drug classes, dosage, and routes of administration), and error consequence (presence or absence of an ADR and its seriousness).

The error setting referred to the place of occurrence of the error, i.e., hospital or community setting. The latter included homes, medical-social institutions, community pharmacies, and outpatient clinics. The stages of the medication-use process were classified as prescribing, dispensing, preparation, administration, and others (including monitoring error). The types of error were categorized as per the French National Agency for Medicines and Health Products Safety: wrong drug, wrong dose, wrong technique, wrong route, wrong patient, wrong duration/time, expired, deteriorated or not well conserved drug, and other medication errors (omission error, wrong rate, and other types defined as any error not fitting into the above pre-specified categories). The causes of error were categorized as related to products, healthcare professionals, patients, or to the computerized system, based on the classification of the Société Française de Pharmacie Clinique for medication error causes. ${ }^{21}$ The medications involved in errors were classified according to the WHO Anatomical Therapeutic Chemical (ATC) classification system second level. ${ }^{22}$ Regarding the seriousness, an ADR associated with medication error was considered serious if it meets one or more of the following pharmacovigilance criteria: results in death, is lifethreatening, requires inpatient hospitalization or prolongation of existing hospitalization, results in persistent or significant disability or incapacity, results in a congenital anomaly (birth defect), or is otherwise medically significant (i.e., effect judged as serious by a healthcare professional). ${ }^{19}$ 
Azar C, Allué D, Valnet-Rabier MB, Chouchana L, Rocher F, Durand D, Grené-Lerouge N, Saleh N, Maison P. Patterns of medication errors involving pediatric population reported to the French Medication Error Guichet. Pharmacy Practice 2021 AprJun;19(2):2360.

https://doi.org/10.18549/PharmPract.2021.2.2360

\section{Data cleaning}

The quality and consistency of data were verified by reviewing the error description text within each medication error report and if needed, by reclassifying medication error stage, type, cause, or severity. In addition, any incompleteness or missing data were cross-checked against the original report.

\section{Statistical analysis}

Descriptive results were presented as frequencies and percentages. To compare the reported medication errors between pediatric and adult populations, we performed bivariate and multivariate analyses in the hospital and community settings. In each setting, a logistic regression analysis using Backward Stepwise method was performed. Two subanalyses limited to actual medication errors with
$A D R$, and actual medication errors with serious ADR were also conducted in each setting. The independent variables concerned the medication errors characteristics (drug classes, routes of administration, classification in terms of actual or potential medication error, stages, types, and causes of error). The characteristics that had a p-value $<0.2$ in the bivariate analysis were included in the logistic regression model in which pediatric versus adult reported medication error was the dependent variable. Multivariate analyses were systematically adjusted for the reporting year, source of declarations (including the regional pharmacovigilance centers network, pharmaceuticals laboratories, healthcare professionals, and patients), and gender. The strength of association between the dependent variable and each independent variable was assessed by calculating the adjusted odds ratio (aOR) and its respective $95 \%$ confidence interval $(\mathrm{Cl})$. The $\mathrm{p}$-values

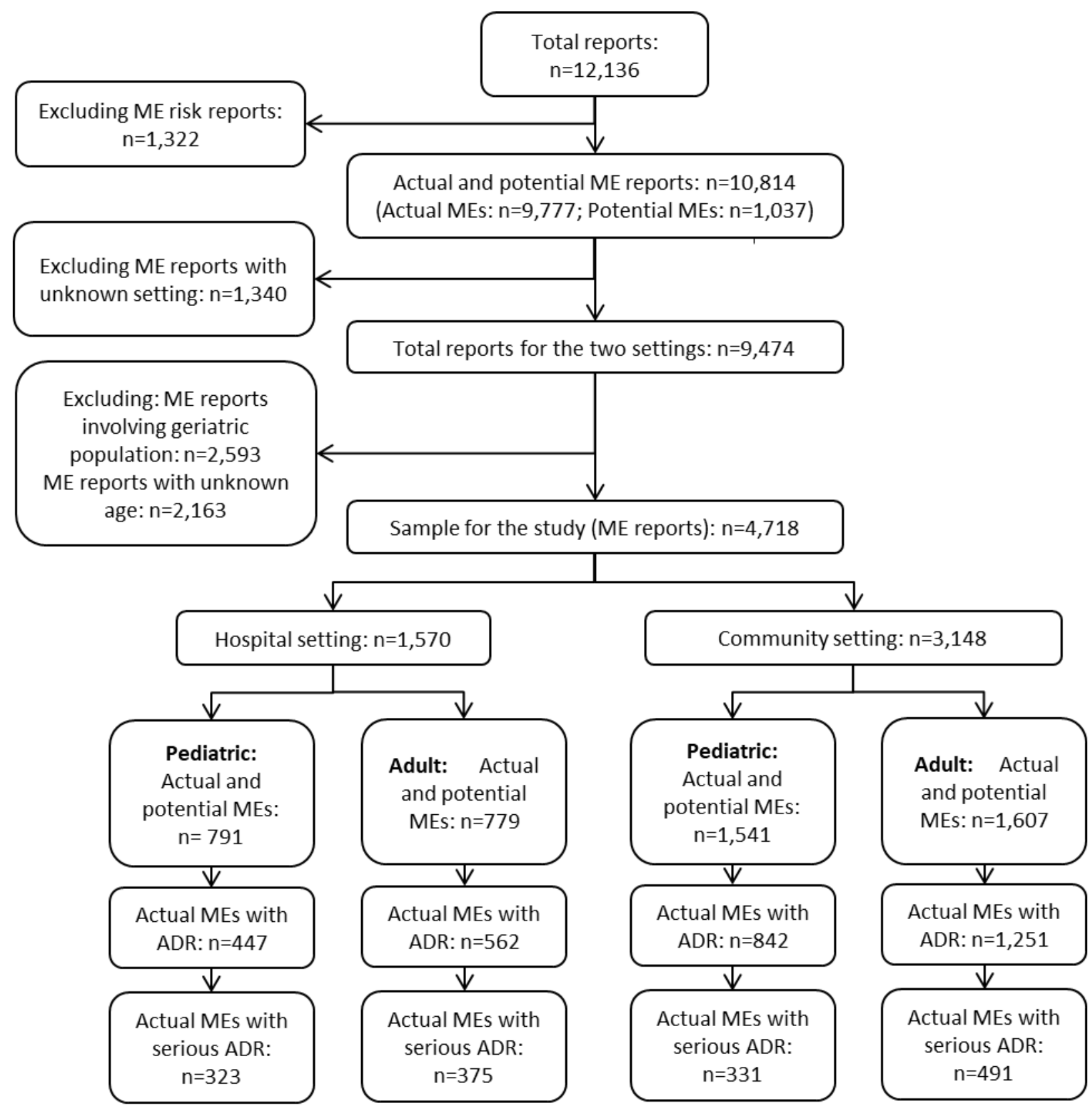

Figure 1. Flowchart of the medication errors reported to the French Medication Error Guichet between 2013 and 2017. ADR: adverse drug reaction; ME: medication error. 
$<0.05$ were considered statistically significant. Statistical analyses were performed using the SPSS version 20. As our analysis intended to generate age- and setting-specific results, reports with missing data for these variables were excluded.

\section{Ethical considerations}

Medication errors data were presented anonymously in the database. An authorization was granted from the Commission Nationale de I'Informatique et des Libertés to the National Agency for Medicines and Health Products Safety to manage the French Medication Error Guichet.

\section{RESULTS}

Between 2013 and 2017, 12,136 medication error reports were submitted to the French Medication Error Guichet. The flowchart of the reports is detailed in Figure 1. Among the 12,136 total medication error reports, 1,322 reports of medication error risk, and 2,593 reports involving geriatric population were not included. Concerning missing data, 1,340 reports with unknown error setting, and 2,163 reports with unknown age data were excluded. Finally, 4,718 reports on actual and potential medication errors in pediatrics and adults in the hospital and community settings were included in the analysis.

\section{Hospital setting}

The analysis was based on 1,570 actual and potential medication errors, reported for both pediatric ( $n=791$, $50.4 \%$ ) and adult ( $n=779,49.6 \%)$ populations (Table 1$)$. The most frequently drug classes reported in pediatric medication errors were antibacterials for systemic use ( $n=121,15.7 \%)$, analgesics ( $n=104,13.5 \%)$, and blood substitutes and perfusion solutions ( $n=94,12.2 \%)$. Regarding routes of administration, the injectable route ( $n=453,65.8 \%$ ) was the most commonly reported in pediatric medication errors. In addition, the most frequently reported error stage in pediatrics was the administration stage $(n=565,71.5 \%)$, and that for error type was the wrong dose $(n=391,49.6 \%)$. Concerning the reported medication error causes in pediatrics, they were mainly related to healthcare professionals ( $n=590,76.6 \%$ ). For the adult population, the most commonly drug classes involved in the medication errors included: analgesics ( $n=73,9.5 \%)$, psycholeptics ( $n=68,8.8 \%$ ), and antibacterials for systemic use $(n=61,7.9 \%)$. Besides, the injectable route of administration ( $n=436,61.4 \%$ ), the administration stage $(n=584,75.2 \%)$, the wrong dose error type $(n=252,32.4 \%)$, and the healthcare professional-related causes $(n=562$, $75.1 \%$ ) were the most frequently reported in the medication errors. The multivariate analysis showed that antibacterials for systemic use, analgesics, blood

\begin{tabular}{|c|c|c|c|c|}
\hline Medication errors characteristics & Adult (N=779), n (\%) & Pediatric (N=791), n (\%) & aOR $[95 \% \mathrm{Cl}] \ddagger$ & p-value \\
\hline \multicolumn{5}{|l|}{ Drug classes $^{+}$} \\
\hline Other ATC classes & $504(65.5)$ & $387(50.3)$ & Reference & N/A \\
\hline J01 (Antibacterials for systemic use) & $61(7.9)$ & $121(15.7)$ & 2.54 [1.57:4.11] & $<0.001$ \\
\hline N02 (Analgesics) & $73(9.5)$ & $104(13.5)$ & $1.59[1.03: 2.45]$ & 0.035 \\
\hline B05 (Blood substitutes and perfusion solutions) & $34(4.4)$ & $94(12.2)$ & $3.74[2.24: 6.25]$ & $<0.001$ \\
\hline N05 (Psycholeptics) & $68(8.8)$ & $33(4.3)$ & $0.72[0.42: 1.26]$ & 0.252 \\
\hline N03 (Antiepileptics) & $30(3.9)$ & $31(4)$ & $1.55[0.82: 2.95]$ & 0.179 \\
\hline \multicolumn{5}{|l|}{ Routes of administration $^{+}$} \\
\hline Oral route & 245 (34.5) & 195 (28.3) & Reference & N/A \\
\hline Injectable route & $436(61.4)$ & $453(65.8)$ & $1.03[0.74: 1.42]$ & 0.880 \\
\hline Others & $29(4.1)$ & $40(5.8)$ & $2.14[1.10: 4.18]$ & 0.026 \\
\hline \multicolumn{5}{|l|}{ Stages of error $^{\dagger}$} \\
\hline Administration & $584(75.2)$ & 565 (71.5) & N/A & N/A \\
\hline Prescribing & $128(16.5)$ & $123(15.6)$ & N/A & N/A \\
\hline Preparation & $26(3.3)$ & $56(7.1)$ & N/A & N/A \\
\hline Dispensing & 28( & $36(4.6)$ & N/A & N/A \\
\hline Others (including monitoring error) & 11( & & N/A & N/A \\
\hline \multicolumn{5}{|l|}{ Types of error $^{+}$} \\
\hline Wrong drug (including wrong form) & $4.3)$ & 150 & Reference & N/A \\
\hline Wrong dose & $252(32.4)$ & 391 (49.6) & $2.51[1.71: 3.68]$ & $<0.001$ \\
\hline Wrong technique & $49(6.3)$ & $54(6.8)$ & $1.18[0.66: 2.10]$ & 0.578 \\
\hline Wrong route & $43(5.5)$ & $41(5.2)$ & $1.71[0.94: 3.13]$ & 0.082 \\
\hline Expired, deteriorated or not well conserved drug & $9(1.2)$ & $25(3.2)$ & $5.16[1.78: 15.0]$ & 0.003 \\
\hline Wrong duration/ wrong time & $30(3.9)$ & $16(2)$ & $1.11[0.48: 2.58]$ & 0.807 \\
\hline Wrong patient & $55(7.1)$ & 15 (1.9) & $0.51[0.22: 1.18]$ & 0.116 \\
\hline Others (omission error, wrong rate, other types) & $150(19.3)$ & $97(12.3)$ & $0.93[0.59: 1.49]$ & 0.773 \\
\hline \multicolumn{5}{|l|}{ Related causes $^{\dagger}$} \\
\hline Product & $85(11.4)$ & $106(13.8)$ & Reference & N/A \\
\hline Healthcare professionals & $562(75.1)$ & $590(76.6)$ & $1.48[0.92: 2.38]$ & 0.105 \\
\hline Patient & $52(7)$ & $33(4.3)$ & $0.84[0.40: 1.74]$ & 0.630 \\
\hline Computerized system & $41(5.5)$ & $33(4.3)$ & $0.74[0.28: 1.93]$ & 0.531 \\
\hline Others & $8(1.1)$ & $8(1)$ & $1.53[0.28: 8.46]$ & 0.629 \\
\hline \multicolumn{5}{|c|}{$\begin{array}{l}\text { aOR: adjusted odds ratio; ATC: Anatomical Therapeutic Chemical classification system; Cl: confidence interval; N/A: not applicable } \\
\text { (reference or excluded from the final model). } \\
\text { 'The sum of the frequencies in each group of population may be less than the total number of reports in this group due to missing } \\
\text { data. } \\
{ }^{\prime} \text { The multivariate analysis was adjusted for year, source of declarations and gender. }\end{array}$} \\
\hline
\end{tabular}


substitutes and perfusion solutions, non-oral non-injectable routes of administration, wrong dose, and expired, deteriorated or not well conserved drug were significantly more likely to be associated with reported medication errors in hospitalized pediatrics compared with adults (Table 1). The breakdown of drug classes frequently reported in actual and potential medication errors in pediatrics, and more likely to be associated with medication errors in pediatrics compared with adults is available in Online appendix Table 1.

The results of the subanalysis concerning actual medication errors with ADR showed that antibacterials for systemic use (aOR=1.92; $95 \% \mathrm{Cl} 1.13: 3.26)$, analgesics $(\mathrm{aOR}=1.63 ; 95 \% \mathrm{Cl}$ 1.05:2.53), blood substitutes and perfusion solutions (aOR=3.75; $95 \% \mathrm{Cl}$ 2.18:6.47) were significantly more likely to be associated with reported medication errors with ADR in pediatrics compared with adults. Regarding error types, wrong dose $(\mathrm{aOR}=2.73 ; 95 \% \mathrm{Cl} 1.82: 4.09)$ and wrong route (aOR=3.11; $95 \% \mathrm{Cl} 1.57: 6.19)$ were significantly more likely to be associated with reported medication errors with ADR in pediatrics compared with adults.

The results of the subanalysis of actual medication errors with serious ADR showed that, regarding drug classes, only blood substitutes and perfusion solutions $(\mathrm{aOR}=3.02 ; 95 \% \mathrm{Cl}$ 1.59:5.72) were significantly more likely to be associated with reported medication errors with serious ADR in pediatrics compared with adults. Concerning error types, wrong dose $(\mathrm{aOR}=2.89 ; 95 \% \mathrm{Cl} 1.79: 4.66)$, wrong route (aOR=2.74; $95 \% \mathrm{Cl}$ 1.22:6.15), and wrong technique (aOR=2.28; $95 \% \mathrm{Cl} 1.01: 5.19$ ) were significantly more likely to be associated with reported pediatric medication errors with serious ADR (Online appendix Table 2). The classification of medication error reports regarding types of ADR in pediatric and adult populations in hospital setting is available in Online appendix Table 3.

\section{Community setting}

The analysis was based on 3,148 actual and potential medication error reports for both pediatric $(n=1,541,49 \%)$ and adult ( $n=1,607,51 \%)$ populations (Table 2). In pediatrics, the most frequently reported drug classes were vaccines ( $n=389,25.7 \%)$, antibacterials for systemic use ( $n=157,10.4 \%)$, and analgesics $(n=117,7.7 \%)$. The oral route of administration ( $n=722,48.9 \%$ ) was the most commonly involved in the reported medication errors in pediatrics. The administration stage ( $n=1,214,78.9 \%)$ accounted for the majority of the pediatric medication error reports. The most frequently reported error type in pediatrics was the wrong dose $(n=549,35.7 \%)$. Concerning error causes, patient-related causes $(n=797,52.9 \%)$ were the most commonly reported in pediatric medication errors. For the adult population, the most commonly reported drug class involved in the medication errors was analgesics $(n=260,16.4 \%)$. Besides, the oral route of administration ( $n=1,057,69.1 \%)$, the administration stage

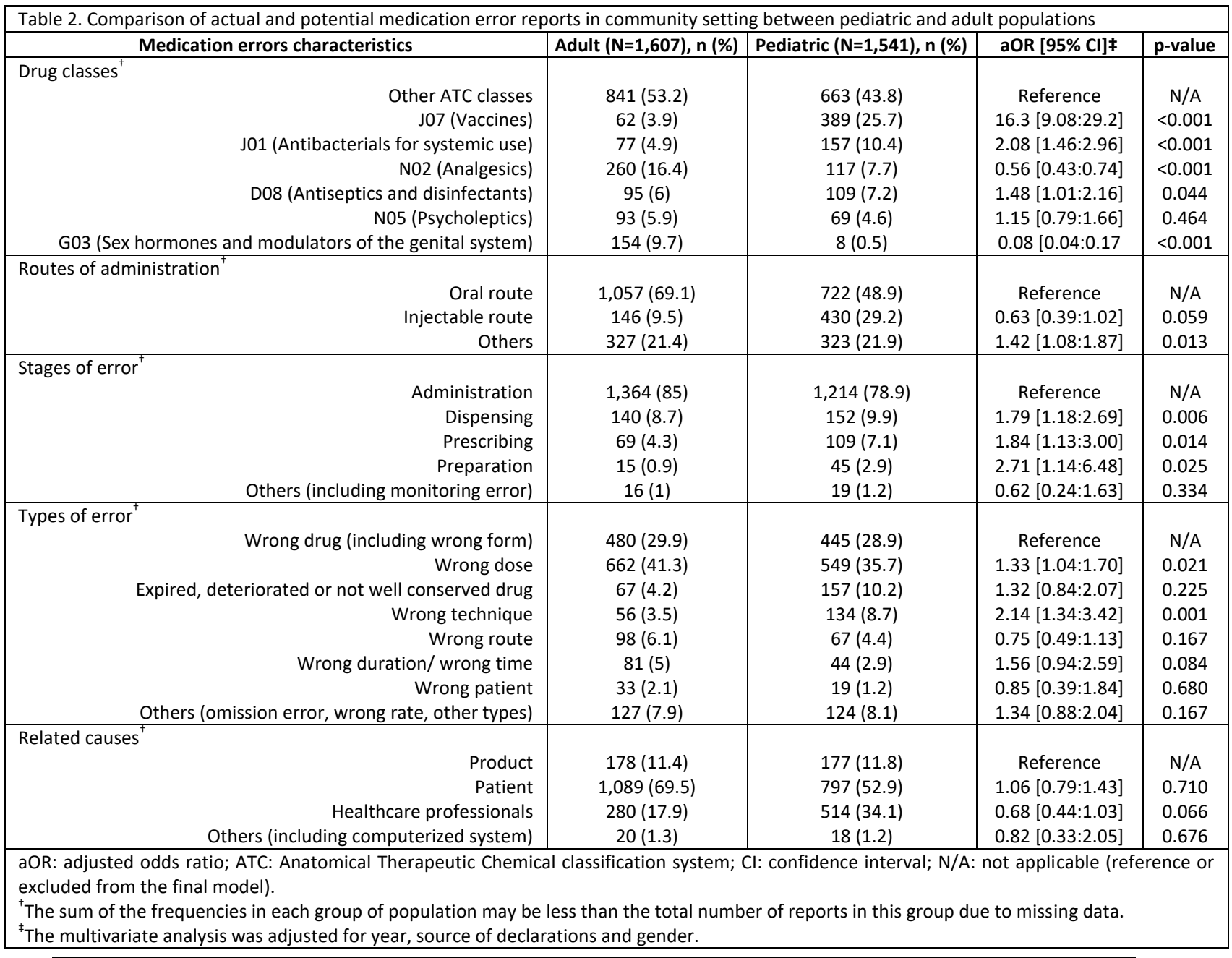


( $n=1,364,85 \%)$, the wrong dose error type $(n=662,41.3 \%)$, and the patient-related causes $(n=1,089,69.5 \%)$ were the most frequently reported in the medication errors. According to the multivariate analysis, antibacterials for systemic use, vaccines, antiseptics and disinfectants, nonoral non-injectable routes of administration, prescribing error, dispensing error, preparation error, wrong dose, and wrong technique were significantly more likely to be associated with reported medication errors in pediatrics compared with adults (Table 2). The breakdown of drug classes frequently reported in actual and potential medication errors in pediatrics, and more likely to be associated with medication errors in pediatrics compared with adults is available in Online appendix Table 4.

The results of the subanalysis of actual medication errors with ADR showed that antiseptics and disinfectants drug class (aOR=1.79; $95 \% \mathrm{Cl} 1.25: 2.56)$, dispensing error (aOR=1.54; $95 \% \mathrm{Cl} 1.03: 2.31$ ), and wrong technique error type $(\mathrm{aOR}=2.71 ; 95 \% \mathrm{Cl} 1.47: 5.00)$ were significantly more likely to be associated with reported medication errors with ADR in pediatrics compared with adults.

The results of the subanalysis of actual medication errors with serious ADR showed that vaccines ( $a O R=10.4 ; 95 \% \mathrm{Cl}$ 3.54:30.6) and psycholeptics (aOR=2.42; $95 \% \mathrm{Cl} 1.36: 4.31)$ drug classes were significantly more likely to be associated with reported medication errors with serious ADR in pediatrics compared with adults (Online appendix Table 5). The classification of medication error reports regarding types of $A D R$ in pediatric and adult populations in community setting is available in Online appendix Table 6.

\section{DISCUSSION}

We analyzed 4,718 medication errors reported to the national French Medication Error Guichet between 2013 and 2017. We comprehensively described medication errors in pediatrics, and identified pertaining specific patterns, in comparison with adults, in each of the hospital and community settings. We deepened our analyses with an exploration of medication errors with ADR, and serious $A D R$. Our findings generate important information for future error-prevention measures in pediatrics, and pave the way for interventional research targeting the needs of this population, with the ultimate goal of enhancing patient safety.

Both in hospital and community settings, frequently reported in pediatrics were wrong dose errors, and those involving antibacterials for systemic use. Specifically, these two characteristics were more likely to be associated with reported medication errors in pediatrics compared with adults. Our findings reiterate the dominance of dosing errors in the pediatric population. For instance, using data from national reporting systems, dosing errors were the most encountered types, accounting for $47.7 \%$ of errors in the hospital setting in Denmark, and $62.5 \%$ of errors in the community in Ireland. ${ }^{16,23}$ Medication dosing in pediatrics bears a high risk of error, due to the complicated drug doses calculations based on patient's age, weight, or body surface area, the increased need for drug dilutions and manipulations subsequent to the lack of pediatric formulations, and the presence of multiple dosing devices used for delivering medications at home, possibly leading to confusion. ${ }^{91,24,25}$ Although these errors are a longstanding problem in pediatrics, the literature does not provide to-date conclusive evidence on effective interventions in this regards. ${ }^{26,27}$ In the hospital setting, computerized physician order entry, unit dose dispensing systems, and educational/risk management programs are suggested to reduce dosing errors. ${ }^{26}$ For example, through a recent systematic review of the literature, Gates et al. found that dosing errors were less prevalent in hospitals with computerized physician order entry, but without evidence that this result represented a causal relationship. $^{27}$ In the community setting, through a randomized controlled trial, Yin et al. showed that providing parents with dosing tools more closely matched to prescribed dose volumes, pictographic instructions, and milliliter-only units on labels and tools are promising strategies for reducing pediatric dosing errors. ${ }^{28}$ There is a pressing need for research employing robust controlled designs to assess the true impact of different interventions on dosing errors and associated harm to patients.

The involvement of antibacterials for systemic use in pediatric medication errors is also commonly reported elsewhere, with proportions reaching $27.2 \%$ in the hospital setting and $17 \%$ in the community. ${ }^{16,23}$ Antibiotics are extensively used in pediatrics, and subject to overtreatment through pressure from parents on clinicians to prescribe them. ${ }^{29,30}$ These factors potentially explain the common involvement of antibacterials in reported medication errors. A French study using a national reimbursement claims database showed that half $(49 \%)$ the children received antibacterials for systemic use. ${ }^{31}$ An opportunity may exist in decreasing unnecessary exposure to antibacterials, and the medication errors that occur with their use.

In our analysis, administration stage topped the reported medication errors in adult and pediatric populations, in both settings. The common citation of administration errors is probably because they are the most visible and closest to the patient. $^{32}$ Specifically, our findings in pediatrics are supported by other studies. Through a systematic review of the literature, Miller et al. found administration error occurrence between 72 and 75 in every 100 reported medication errors. ${ }^{33}$ Recent estimates also highlight this issue, whereby administration errors accounted between $42.5 \%$ and $54 \%$ of pediatric medication errors. ${ }^{14,15}$ Of interest, Kaushal et al. found that harmful errors occurred most commonly at the drug administration stage by parents. ${ }^{34}$ Interventional studies in hospital medication administration errors explored barcode medicine administration, electronic prescribing, education and training, use of smart pumps, and standard concentration. $^{35}$ However, evidence is not conclusive regarding their impact or effects on reducing errors. ${ }^{35}$ In the community, all caregivers including parents, extended family members, and school nurses should be adequately trained on how to appropriately administer the medication to children. ${ }^{36}$

In the hospital setting, our findings of analgesics, and blood substitutes and perfusion solutions being frequently reported in medication errors in pediatrics are in line with 
the literature. ${ }^{23,37}$ For instance, in the national study by Rishoej et al., both of these drug classes were commonly involved in reported medication errors, with respective proportions of $13 \%$ and $6 \% .{ }^{23}$ Of interest, our comparison with reported medication errors in adults indicates that errors involving analgesics, and blood substitutes and perfusion solutions related more to pediatrics. Through an observational study, Jimenez et al. also found that pediatrics had higher medication errors related to electrolytes and total parenteral nutrition compared with adults $(19.9 \%$ vs. $8.3 \%) .{ }^{14}$ Accordingly, prevention strategies targeting analgesics, and blood substitutes and perfusion solutions may considerably enhance pediatric patient safety, especially that these classes encompass high-alert medications in pediatrics, such as opioids, and parenteral nutrition. ${ }^{38}$ Within this scope, we identified that blood substitutes and perfusion solutions related more to reported medication errors with serious ADR in pediatrics. For instance, one of the described serious ADRs was electrolyte disorders such as hyperkalemia or hyperglycemia resulting from errors with solutions for parenteral nutrition (data not shown).

In line with the literature, wrong route and wrong technique error types were not commonly reported in pediatric and adult medication errors in hospital setting. ${ }^{23,32,39,40}$ Importantly, our findings suggest that these error types were more likely to be associated with reported medication errors with serious ADR in pediatrics compared with adults. Data from the Finnish Poison Information Centre indicate that incorrect route of administration error type occurred mainly in hospitals. ${ }^{40}$ This type resulted in the most serious medication errors. ${ }^{40}$ Children under 10 years of age were particularly exposed to this error type. ${ }^{40}$

In the community setting, vaccines were the drug class most frequently involved in reported errors in pediatrics. Common involvement of vaccines in pediatric medication errors was also reported elsewhere. ${ }^{15}$ This comes parallel to the substantial exposure to vaccinations throughout early childhood, and the complex vaccination schedule. ${ }^{41}$ Using data from the United Kingdom National Reporting and Learning System, the study of Rees et al. conducted to characterize the pediatric safety incidents occurring in family practice, found that vaccine-related incidents were the most frequently described, with wrong time, wrong dose, and wrong vaccine error types, being the most frequently reported. These vaccination incidents resulted in harm in $70.6 \%$ of cases. ${ }^{42}$ Vaccines are nonemergency drugs given in specific, controlled circumstances, and pertaining error types are associated with predictable vaccine-related human factors challenges; the targeting of which presents a valuable opportunity to prevent errors. $^{15,41}$

This study adds evidence that medication errors involving analgesics are commonly reported in pediatrics in the community. ${ }^{13,16,43}$ Nevertheless, our analysis showed that these agents were less likely to be associated with reported medication errors in pediatrics compared with adults. In contrast, although psycholeptics were infrequently reported in community pediatric medication errors, as shown elsewhere, our study found that they related more to reported medication errors with serious ADR in pediatrics compared with adults. ${ }^{13}$ Based on the National Poison Data System in the United States from 2000 to 2012, Kamboj et al. found that atypical antipsychotics- a group of psycholeptics were associated with $32.1 \%$ of medication errors among children aged 6 to 19 years, compared with $20.6 \%$ among adults aged 20 years or above. ${ }^{44}$ Our results thus join the emerging literature in suggesting a pediatric-specific pattern concerning medication errors involving psycholeptics. Finding effective targeted strategies for reducing pertaining medication errors and associated harm is crucial.

Noteworthy, we report a discordance with the former literature concerning medication errors involving cough and cold preparations. While this drug class was previously commonly involved in medication errors in children in the community, it was not identified as such in our analysis. ${ }^{13,16,43}$ Smith et al., in their study spanning 20022012, showed a sharp decline in both the frequency and rate of errors involving cough and cold preparations from 2005 through 2012. ${ }^{13}$ Decline in pertaining errors could be related to the decreased use of these agents, which might be attributed to the recommendation against the use of over-the-counter cough and cold preparations among young children. ${ }^{45}$ Indeed, recent evidence did not identify these agents in reported medication errors in pediatrics. ${ }^{15}$

In the community, wrong technique error type was not frequently reported in pediatrics; yet, our comparative analysis showed that this error type is pediatric-specific, relating more to reported medication errors, as well as medication errors with ADR in this population. This may be explained by the increased need for drug manipulation in pediatric care that is mainly driven by the lack of commercially-available, age-appropriate formulations. ${ }^{11,24}$ Other reasons include parents misunderstanding medication preparation instructions, or altering the technique for administration from the physician instructions due to the lack of proper equipment, or because the recommended technique did not work at home. $^{46,47}$ Suggested actions include interventions to enhance carers' understanding of administration techniques through proper and precise instructions, having appropriate equipment at home, in addition to routine provider inquiry about problems in daily medication use. $^{47,48}$

Finally, as medication errors were reported throughout the medication use process in both settings, involvement of all actors along the continuum of care is crucial to ensure patient safety.

\section{Strengths and limitations}

This study is the first to comprehensively analyze pediatric medication errors reported to the French Medication Error Guichet, over a five-year period. Using a large national database, this study allowed delineating pediatric-specific medication error patterns in comparison with adults, in each of the hospital and community settings. Furthermore, we complemented our results with comparative analyses of reported medication errors with $A D R$ and serious $A D R$.

The analysis bore numerous challenges including the use of retrospective secondary data based on a reporting 

medication errors involving pediatric population reported to the French Medication Error Guichet. Pharmacy Practice 2021 Apr-

system. ${ }^{49,50}$ Particularly, missing data have decreased our initial sample size; nevertheless, since the sample remained large, it is unlikely that this resulted in a substantial loss of statistical power. Underreporting of medication errors is another limitation. ${ }^{50}$ Many barriers to reporting have been described, including fear of disciplinary actions, fear of lack of confidentiality, loss of self-esteem, lack of time, lack of awareness that an error has occurred, and lack of postreporting feedback. ${ }^{51,52}$ However, our reporting system is anonymous and non-punitive. Although our data originated from a national system, they do not convey a representative picture of all medication errors. Yet, the characteristics of the reported medication errors in our analysis are comparable with those of other medication error reporting system-based studies. ${ }^{16,23,37}$ Concerning the comparison between pediatrics and adults, although the reported medication errors in each comparison group originated from the same reporting system, many other aspects should be taken into account including the differences in the burden of disease, the healthcare providers involved, and the types of medications used in these two populations.

\section{CONCLUSIONS}

Pediatrics are not little adults; they require particular attention in medication use. Our study characterized medication errors in pediatrics, and identified specific medication error patterns in this population, compared with adults. Drug classes particularly implicated in pediatric medication errors included antibacterials for systemic use, analgesics, blood substitutes and perfusion solutions, vaccines, and psycholeptics. Other error-prone areas involved primarily the administration stage; in addition to wrong dose, wrong technique, and wrong route types. Our results hold important implications for health professionals, caregivers, manufacturers, and policy makers, as well as researchers with respect to focused measures to enhance pediatric medication safety.

\section{ACKNOWLEDGMENTS}

We acknowledge Frederic Rannou from the French National Agency for Medicines and Health Products Safety, for technical assistance in extracting the data. We also acknowledge the important contributions of the Regional Pharmacovigilance Centers network in data collection.

\section{CONFLICT OF INTEREST}

The Authors declare that there is no conflict of interest.

\section{FUNDING}

This research did not receive any specific grant from funding agencies in the public, commercial, or not-forprofit sectors.

\section{AUTHOR ROLES (CRediT)}

Conceptualization: CA, PM.

Data curation: CA, DA, MBVR, LC, FR, DD, NGL.

Formal analysis: $C A$.

Investigation: DA, MBVR, LC, FR, DD, NGL.

Methodology: CA, NS, PM.

Project administration: PM.

Supervision: NS, PM.

Writing - original draft: CA.

Writing - review \& editing: CA, DA, MBVR, LC, FR, DD, NGL, NS, PM.

\section{References}

1. Kohn LT, Corrigan J, Donaldson MS, eds. To err is human: building a safer health system. Washington, DC: National Academy Press; 2000.

2. Leape LL. Institute of Medicine medical error figures are not exaggerated. JAMA. 2000;284(1):95-97. https://doi.org/10.1001/jama.284.1.95

3. Stelfox HT, Palmisani S, Scurlock C, Orav EJ, Bates DW. The "To Err is Human" report and the patient safety literature. Qual Saf Health Care. 2006;15(3):174-178. https://doi.org/10.1136/qshc.2006.017947

4. Wittich CM, Burkle CM, Lanier WL. Medication errors: an overview for clinicians. Mayo Clin Proc. 2014;89(8):1116-1125. https://doi.org/10.1016/j.mayocp.2014.05.007

5. World Health Organization. WHO launches global effort to halve medication-related errors in 5 years https://www.who.int/news-room/detail/29-03-2017-who-launches-global-effort-to-halve-medication-related-errors-in-5years (accessed Sep 30, 2019).

6. Elliott RA, Camacho E, Campbell F, et al. Prevalence and economic burden of medication errors in the NHS in England. http://www.eepru.org.uk/prevalence-and-economic-burden-of-medication-errors-in-the-nhs-in-england-2/ (accessed Oct 1 , 2019).

7. Michel P, Quenon JL, Djihoud A, Tricaud-Vialle S, de Sarasqueta AM. French national survey of inpatient adverse events prospectively assessed with ward staff. Qual Saf Health Care. 2007;16(5):369-377. https://doi.org/10.1136/qshc.2005.016964

8. World Health Organization. WHO global patient safety challenge: medication without harm. https://www.who.int/patientsafety/medication-safety/medication-without-harm-brochure/en/ (accessed Sep 30, 2019).

9. Woo Y, Kim HE, Chung S, Park BJ. Pediatric medication error reports in Korea adverse event reporting system database, 1989-2012: comparing with adult reports. J Korean Med Sci. 2015;30(4):371-377. https://doi.org/10.3346/jkms.2015.30.4.371

10. Kaushal R, Bates DW, Landrigan $C$, et al. Medication errors and adverse drug events in pediatric inpatients. JAMA. 2001;285(16):2114-2120. https://doi.org/10.1001/jama.285.16.2114

11. Wong IC, Ghaleb MA, Franklin BD, Barber N. Incidence and nature of dosing errors in paediatric medications: a systematic review. Drug Saf. 2004;27(9):661-670. https://doi.org/10.2165/00002018-200427090-00004 
Azar C, Allué D, Valnet-Rabier MB, Chouchana L, Rocher F, Durand D, Grené-Lerouge N, Saleh N, Maison P. Patterns of medication errors involving pediatric population reported to the French Medication Error Guichet. Pharmacy Practice 2021 AprJun;19(2):2360

https://doi.org/10.18549/PharmPract.2021.2.2360

12. Alghamdi AA, Keers RN, Sutherland A, Ashcroft DM. Prevalence and Nature of Medication Errors and Preventable Adverse Drug Events in Paediatric and Neonatal Intensive Care Settings: A Systematic Review. Drug Saf. 2019;42(12):1423-1436. https://doi.org/10.1007/s40264-019-00856-9

13. Smith MD, Spiller HA, Casavant MJ, Chounthirath T, Brophy TJ, Xiang H. Out-of-hospital medication errors among young children in the United States, 2002-2012. Pediatrics. 2014;134(5):867-876. https://doi.org/10.1542/peds.2014-0309

14. Jimenez A, Tran TM, Le B, Le J. Comparative cross-sectional pharmacovigilance study of medication errors in children and adults in community-based hospitals. Asploro J Pediatr Child Health. 2020;2(1):1-12. https://doi.org/10.36502/2020/asjpch.6150

15. Conn RL, Tully MP, Shields MD, Carrington A, Dornan T. Characteristics of Reported Pediatric Medication Errors in Northern Ireland and Use in Quality Improvement. Paediatr Drugs. 2020;22(5):551-560. https://doi.org/10.1007/s40272 $\underline{020-00407-1}$

16. Cassidy N, Duggan E, Williams DJ, Tracey JA. The epidemiology and type of medication errors reported to the National Poisons Information Centre of Ireland. Clin Toxicol (Phila). 2011;49(6):485-491. https://doi.org/10.3109/15563650.2011.587193

17. Brophy TJ, Spiller HA, Casavant MJ, Chounthirath T, Smith MD, Xiang H. Medication errors reported to U.S. Poison Control Centers, 2000-2012. Clin Toxicol (Phila). 2014;52(8):880-888. https://doi.org/10.3109/15563650.2014.953168

18. Agence nationale de sécurité du médicament et des produits de santé. [Activity report 2017]. https://www.ansm.sante.fr/var/ansm site/storage/original/application/87c97d5bef977831be05af840a2abd2c.pdf (accessed Oct 2, 2019).

19. Agence nationale de sécurité du médicament et des produits de santé. [Good pharmacovigilance practices] https://www.ansm.sante.fr/Activites/Elaboration-de-bonnes-pratiques/Bonnes-pratiques-de-pharmacovigilance/(offset)/1 (accessed Oct 2, 2019).

20. Agence nationale de sécurité du médicament et des produits de santé. [What is a medication error] https://www.ansm.sante.fr/Declarer-un-effet-indesirable/Erreurs-medicamenteuses/Qu-est-ce-qu-une-erreurmedicamenteuse/(offset)/0 (accessed Oct 2, 2019).

21. Baum T, Beretz L, Bohand X, et al. [La REMED : The review of errors related to drugs and associated devices - a method to improve the quality of care]. https://sfpc.eu/wp-content/uploads/2019/11/Manuel de la remed- jan 2013 version dfinitive 300114-copie.pdf (accessed Oct 1, 2019)..

22. WHO Collaborating Centre for Drug Statistics Methodology. International language for drug utilization research ATC/DDD https://www.whocc.no (accessed Sep 30, 2019)

23. Rishoej RM, Almarsdóttir AB, Christesen HT, Hallas J, Kjeldsen LJ. Medication errors in pediatric inpatients: a study based on a national mandatory reporting system. Eur J Pediatr. 2017;176(12):1697-1705. https://doi.org/10.1007/s00431$\underline{017-3023-8}$

24. World Health Organization. WHO expert committee on specifications for pharmaceutical preparations. [https://www.who.int/medicines/areas/quality safety/quality assurance/expert committee/trs 970/en/ (accessed Sep 30, 2019).

25. Mehndiratta S. Strategies to reduce medication errors in pediatric ambulatory settings. J Postgrad Med. 2012;58(1):47-53. https://doi.org/10.4103/0022-3859.93252

26. Conroy S, Sweis D, Planner C, et al. Interventions to reduce dosing errors in children: a systematic review of the literature. Drug Saf. 2007;30(12):1111-1125. https://doi.org/10.2165/00002018-200730120-00004

27. Gates PJ, Meyerson SA, Baysari MT, Westbrook JI. The Prevalence of Dose Errors Among Paediatric Patients in Hospital Wards with and without Health Information Technology: A Systematic Review and Meta-Analysis. Drug Saf. 2019;42(1):13-25. https://doi.org/10.1007/s40264-018-0715-6

28. Yin HS, Parker RM, Sanders LM, et al. Pictograms, Units and Dosing Tools, and Parent Medication Errors: A Randomized Study. Pediatrics. 2017;140(1):e20163237. https://doi.org/10.1542/peds.2016-3237

29. Størdal K, Wyder C, Trobisch A, Grossman Z, Hadjipanayis A. Overtesting and overtreatment-statement from the European Academy of Paediatrics (EAP). Eur J Pediatr. 2019;178(12):1923-1927. https://doi.org/10.1007/s00431-019$\underline{03461-1}$

30. Bosley H, Henshall C, Appleton JV, Jackson D. A systematic review to explore influences on parental attitudes towards antibiotic prescribing in children. J Clin Nurs. 2018;27(5-6):892-905. https://doi.org/10.1111/jocn.14073

31. Bénard-Laribière A, Jové J, Lassalle R, Robinson P, Droz-Perroteau C, Noize P. Drug use in French children: a population-based study. Arch Dis Child. 2015;100(10):960-965. https://doi.org/10.1136/archdischild-2014-307224

32. Santell JP, Hicks RW, McMeekin J, Cousins DD. Medication errors: experience of the United States Pharmacopeia (USP) MEDMARX reporting system. J Clin Pharmacol. 2003;43(7):760-767. https://doi.org/10.1177/0091270003254831

33. Miller MR, Robinson KA, Lubomski LH, Rinke ML, Pronovost PJ. Medication errors in paediatric care: a systematic review of epidemiology and an evaluation of evidence supporting reduction strategy recommendations. Qual Saf Health Care. 2007;16(2):116-126. https://doi.org/10.1136/qshc.2006.019950

34. Kaushal R, Goldmann DA, Keohane CA, et al. Adverse drug events in pediatric outpatients. Ambul Pediatr. 2007;7(5):383-389. https://doi.org/10.1016/i.ambp.2007.05.005

35. Ameer A, Dhillon S, Peters MJ, Ghaleb M. Systematic literature review of hospital medication administration errors in children. Integr Pharm Res Pract. 2015;4:153-165. https://doi.org/10.2147/iprp.s54998

36. Kahn S, Abramson EL. What is new in paediatric medication safety?. Arch Dis Child. 2019;104(6):596-599 https://doi.org/10.1136/archdischild-2018-315175

37. Manias E, Kinney S, Cranswick N, Williams A. Medication errors in hospitalised children. J Paediatr Child Health. 2014;50(1):71-77. https://doi.org/10.1111/ipc.12412 
Azar C, Allué D, Valnet-Rabier MB, Chouchana L, Rocher F, Durand D, Grené-Lerouge N, Saleh N, Maison P. Patterns of medication errors involving pediatric population reported to the French Medication Error Guichet. Pharmacy Practice 2021 AprJun;19(2):2360

https://doi.org/10.18549/PharmPract.2021.2.2360

38. Maaskant JM, Eskes A, van Rijn-Bikker P, Bosman D, van Aalderen W, Vermeulen H. High-alert medications for pediatric patients: an international modified Delphi study. Expert Opin Drug Saf. 2013;12(6):805-814. https://doi.org/10.1517/14740338.2013.825247

39. Wahr JA, Shore AD, Harris LH, et al. Comparison of intensive care unit medication errors reported to the United States' MedMarx and the United Kingdom's National Reporting and Learning System: a cross-sectional study. Am J Med Qual. 2014;29(1):61-69. https://doi.org/10.1177/1062860613482964

40. Kuitunen T, Kuisma P, Hoppu K. Medication errors made by health care professionals. Analysis of the Finnish Poison Information Centre data between 2000 and 2007. Eur J Clin Pharmacol. 2008;64(8):769-774 https://doi.org/10.1007/s00228-008-0496-4

41. Bundy DG, Shore AD, Morlock LL, Miller MR. Pediatric vaccination errors: application of the " 5 rights" framework to a national error reporting database. Vaccine. 2009;27(29):3890-3896. https://doi.org/10.1016/j.vaccine.2009.04.005

42. Rees $P$, Edwards A, Panesar S, et al. Safety incidents in the primary care office setting. Pediatrics. 2015;135(6):10271035. https://doi.org/10.1542/peds.2014-3259

43. McD Taylor D, Robinson J, MacLeod D, MacBean CE, Braitberg G. Therapeutic errors among children in the community setting: nature, causes and outcomes. J Paediatr Child Health. 2009;45(5):304-309. https://doi.org/10.1111/i.14401754.2008.01462.x

44. Kamboj A, Spiller HA, Casavant MJ, Chounthirath T, Hodges NL, Smith GA. Antidepressant and antipsychotic medication errors reported to United States poison control centers. Pharmacoepidemiol Drug Saf. 2018;27(8):902-911. https://doi.org/10.1002/pds.4554

45. Briars LA. The Latest Update on Over-the-Counter Cough and Cold Product Use in Children. J Pediatr Pharmacol Ther. 2009;14(3):127-131. https://doi.org/10.5863/1551-6776-14.3.127

46. Walsh KE, Roblin DW, Weingart SN, et al. Medication errors in the home: a multisite study of children with cancer. Pediatrics. 2013;131(5):e1405-e1414. https://doi.org/10.1542/peds.2012-2434

47. Walsh KE, Mazor KM, Stille CJ, et al. Medication errors in the homes of children with chronic conditions. Arch Dis Child. 2011;96(6):581-586. https://doi.org/10.1136/adc.2010.204479

48. Parand A, Garfield S, Vincent C, Franklin BD. Carers' Medication Administration Errors in the Domiciliary Setting: A Systematic Review. PLoS One. 2016;11(12):e0167204. https://doi.org/10.1371/journal.pone.0167204

49. Dunn SL, Arslanian-Engoren C, DeKoekkoek T, Jadack R, Scott LD. Secondary Data Analysis as an Efficient and Effective Approach to Nursing Research. West J Nurs Res. 2015;37(10):1295-1307. https://doi.org/10.1177/0193945915570042

50. Zhan C, Smith SR, Keyes MA, Hicks RW, Cousins DD, Clancy CM. How useful are voluntary medication error reports? The case of warfarin-related medication errors. Jt Comm J Qual Patient Saf. 2008;34(1):36-45. https://doi.org/10.1016/s1553-7250(08)34006-9

51. Smith, J. Building a safer NHS for patients: improving medication safety. London: Department of Health; 2004.

52. Jeffe DB, Dunagan WC, Garbutt J, et al. Using focus groups to understand physicians' and nurses' perspectives on error reporting in hospitals. Jt Comm J Qual Saf. 2004;30(9):471-479. https://doi.org/10.1016/s1549-3741(04)30055-9 